\title{
MODELO DE SIMULAÇÃO APLICADO AO CONCEITO DA PRODUÇÃO ENXUTA NO ENSINO DE ENGENHARIA DE PRODUÇÃO
}

\section{SIMULATION MODEL APPLIED TO THE LEAN PRODUCTION CONCEPT ON PRODUCTION ENGINEERING EDUCATION}

\author{
Eduardo Guilherme Satolo ${ }^{1}$ \\ ${ }^{1}$ Faculdade Politécnica de Campinas - POLICAMP - Campinas - Brasil \\ engproducao@policamp.edu.br
}

\begin{abstract}
Resumo
A utilização de jogos e simulação têm se difundido atualmente como uma ferramenta de apoio ao ensino. No entanto, estes ainda estão restritos a poucos quando se aborda o ensino de engenharia de produção devido, principalmente, à dificuldade de se criar um jogo. O presente artigo visa suprir esta necessidade apresentando um jogo didático de montagem de aviões de papel. A partir de uma fábrica pré-estruturada, os participantes são envolvidos e estimulados a modificarem o ambiente fabril, por meio dos conhecimentos adquiridos no decorrer do semestre letivo. São tratados diversos tópicos relativos à produção enxuta, como: lotes de produção; padronização do trabalho; simplificação de operações; formação de células de manufatura; cálculo de tempo de ciclo, cálculo de takt time; aumento de velocidade e ritmo de trabalho; redução do tempo de atravessamento; diminuição de transporte; curva de aprendizagem; e atividades que agregam/não agregam valor. Como resultado nota-se, entre diversos aspectos, a melhora por parte dos participantes na compreensão dos ensinamentos teóricos, já que a aplicação da simulação demonstrar possíveis casos e dificuldades que enfrentarão no ambiente fabril.
\end{abstract}

Palavras-chave: simulação; jogo didático; fábrica aviões de papel; sistema de produção enxuta.

\section{Introdução}

Historicamente, a transmissão de conhecimento dentro do ambiente acadêmico é abordada de maneira fragmentada, em disciplinas separadas sem relacionamentos relevantes entre si. Além disso, as informações e os alunos são tratados de maneira padronizada, cuja ênfase da aprendizagem está no professor, ao invés daquele que efetivamente deve aprender, resultando em alunos inertes neste processo educacional, no qual exercem pouca influência (OLIVEIRA et al., 2006).

Trabalhar com o ensino de adultos de maneira fragmentada e sem colocar o aluno como principal cliente do ensino resulta na baixa absorção de conhecimentos. Estudos realizados na área da Andragogia, arte de ensino para adultos, demonstram que os estudantes adultos aprendem apenas 10\% do que ouvem, após 72 horas. Entretanto são capazes de lembrar $85 \%$ do que ouvem, vêm e fazem, após as mesmas 72 horas (BELLAN, 2005). 
Fazer com que o aluno retenha mais do que $10 \%$ do seu conhecimento é uma arte, e traz ao profissional do ensino superior um desafio cada vez maior.

Nos últimos anos, com os avanços da Tecnologia da Informação, diversos recursos foram introduzidos no ambiente escolar para apoiar as ferramentas tradicionais de ensino: lousa e giz. Apresentações multimídia, lousa digital, vídeos, aulas práticas simulando ambientes reais tornaramse mais comuns e permitiram o aumento do conhecimento absorvido por parte dos alunos.

No entanto, em alguns campos do conhecimento ainda é possível utilizar ferramentas de apoio ao ensino pouco empregadas no ambiente educacional, algumas vezes pelo desconhecimento por parte dos docentes, ou pela dificuldade em se elaborar tais ferramentas.

O uso de jogos didáticos é uma alternativa de ensino, pois permite abordar técnicas por meio da simulação do processo produtivo, com o objetivo de melhorar a produtividade da equipe e o aumento do nível de conhecimento absorvido que é passado (DEPEXE et al., 2006).

Os jogos e simulações são consideradas ferramentas pedagógicas eficientes para o ensino, pois permitem explorar estratégias alternativas e suas conseqüências, em um ambiente seguro e próximo do real, com a vantagem de simplificar os elementos vivenciados cotidianamente e inserilos no ambiente escolar. (SCHRAMM; FORMOSO, 2007).

O uso da simulação apresenta diversos benefícios entre os quais: a possibilidade de representação da complexidade de um sistema de produção, a comparação entre projetos alternativos, mensurar os efeitos de diferentes políticas sobre o desempenho do sistema, formar as competências necessárias onde o conhecimento atual não é suficiente, desenvolver as melhores habilidades cognitivas e capacidade crítica, incluir o ambiente econômico no foco gerencial, desenvolver espírito crítico nas decisões, estimular a transposição da aprendizagem. (LAW; KELTON, 2000; PESSÔA; MARQUES FILHO, 2001; FIGUEIREDO; ZAMBOM; SAITO, 2001; ROBINSON, 2003; RAUCH-GEELHAAR; JENKE; THURNES, 2003).

Desta forma, segundo Depexe et al. (2006), estas ferramentas de treinamento, como a simulação, devem ser adaptadas de acordo com a demanda específica de conhecimento, combinando diferentes formas de ensino, métodos e ferramentas que possibilitem a aquisição de competências.

No entanto, o emprego de simulações ainda é pouco explorado no ensino de engenharia de produção devido à dificuldade de se criar um jogo (ANTONIO; WERMECK ; PIRES, 2005). Estas dificuldades podem ser de origem conceitual, relacionadas a restrição na obtenção de informações na literatura de jogos similares e ou pela formação de "reserva de mercado" por parte de seus autores, haja vista que muitos deles são lucrativas fontes de renda em cursos pagos; de origem tecnológica, já que com o uso de novas tecnologias, principalmente as relacionadas com computadores e simuladores, necessita de habilidades extras, tanto dos participantes quanto do 
instrutor; e de origem financeira, com a limitação de recursos para o desenvolvimento e criação dos jogos (PROENÇA JUNIOR, 2003; LEIS et al., 2006).

Neste contexto, o objetivo deste artigo é apresentar um jogo didático como ferramenta de apoio ao ensino da engenharia de produção e do conceito de sistema Lean Production, por meio da simulação de uma linha de produção de aviões de papel, a partir do qual se podem abordar diversos conceitos relativos aos sistemas de produção enxuto.

\section{Breve contextualização do sistema de produção enxuta}

As marcas deixadas pela $2^{\circ}$ Guerra Mundial no Japão fizeram com que as empresas deste país buscassem alternativas para crescer em meio ao caos e ao baixo poder aquisitivo da população. Neste período, iniciou-se o conceito de um sistema produtivo denominado primeiramente Sistema Toyota de Produção.

Os fundamentos desenvolvidos pelo Sistema Toyota de Produção deram origem ao que se denomina atualmente de Sistema de Produção Enxuta (ou Sistema Lean Production). Esse sistema possui como filosofia o emprego da identificação e minimização ou eliminação progressiva das fontes de desperdícios, baseando-se em cinco princípios fundamentais: a definição de valor (i), a partir da visão do cliente e de suas necessidades, sendo então determinadas às atividades necessárias para ofertar o produto ao cliente com o menor nível de desperdício por meio da definição da cadeia de valor (ii). Busca-se então à fabricação do produto usando de um fluxo contínuo (iii); que é disparado apenas quando o cliente efetua o pedido. Ou seja, usando de uma produção puxada (iv). A partir destes quatro princípios e da utilização de melhorias continuas (kaizen) ou melhorias radicais (kaikaku) busca-se alcançar o quinto princípio fundamental que é a perfeição (v) do sistema (WOMACK; JONES; ROSS, 2004; HUNTER, 2004).

Benko e McFarlan (2003) destacam ainda outros aspectos que devem ser contemplados dentro do Sistema de Produção Enxuto, tais como: maior preocupação com aspectos e questões relativas a impactos ambientais; possibilidade de maior interação do cliente final na customização do produto; criação de mecanismos para estimular a fidelidade à marca; montagem modular de componentes e rápidas alterações de configuração do chão-de-fábrica das empresas.

Ao se lecionar o conceito do Sistema de Produção Enxuta, deve-se levar em consideração diversos temas que são interligados e que compõem a denominada filosofia lean. Dentro destes temas estão como: a melhoria contínua por meio do Kaizen, discernimento de uma cultura de aprendizagem, desenvolvimento de liderança e times para implantação, utilização de fluxo continuo para identificação de problemas, utilização de produção puxada, padronização de atividades, controle visual, entre outros (LIKER; MEIER, 2004).

Estes diversos temas associados à aprendizagem do sistema de produção puxado foram 
levantados e destacados por Feld (2000) por meio do estabelecimento de uma classificação das técnicas e ferramentas mais comumente empregadas e que conseqüentemente devem ser ensinadas aos colaboradores durante a implantação do sistema. Para o autor tais técnicas e ferramentas podem ser agrupadas em cinco grandes categorias:

- Fluxo de produção - abrange técnicas relacionadas com trocas físicas, procedimentos de desenvolvimento de produtos e definição de padrões que se fazem necessários. Algumas técnicas e métodos relacionados a esta categoria são: Mapeamento do Fluxo de Valor (MFV); maior grau de customização de processos, produtos e/ou serviços; conceito de takt time; organização de layout celular, dentre outros.

- Organização e cultura - são agrupadas neste conjunto questões relacionadas com a definição de papéis de indivíduos, aprendizado, comunicação e valores partilhados. Algumas técnicas e métodos relacionados a esta categoria são: organização de equipes multifuncionais, empowerment, definição de missão e valores da organização, dentre outros.

- Controle de Processos - aborda técnicas relacionadas com acompanhamento/ monitoramento, controle, estabilização e melhoria do processo de produção. Algumas técnicas e métodos relacionados a esta categoria são: CEP (Controle Estatístico de Processo), SMED (Single Minute Exchange of Die), Programa 5S, TPM (Total Productive Maintenance), Poka Yoke, dentre outros.

- Métricas - engloba técnicas que medem o desempenho, objetivos de melhora e medidas de recompensa para os times de trabalho e colaboradores. Algumas métricas realizadas são: tempo de ciclo, giro de inventário, valor agregado por trabalhador, dentre outros.

- Logística - relaciona regras de funcionamento, técnicas e métodos de planificação e controle de fluxos de materiais internos e externos. Algumas técnicas e métodos relacionados a esta categoria são: JIT (Just in Time), Kanban, classificação ABC, dentre outros.

A elaboração da dinâmica busca contemplar o maior número possível de elementos envoltos a operacionalização do Sistema Lean Production e aos ensinamentos transcorridos aos participantes durante a aula ou treinamento ministrado. É notório que não será possível estabelecer uma dinâmica que envolva $100 \%$ das técnicas e ferramentas aplicadas junto ao sistema de produção enxuta, sendo que para atender aos demais tópicos deve-se utilizar ou elaborar outras simulações.

\section{Método de desenvolvimento do trabalho}

Os novos métodos de ensino apoiados na simulação visam à criação de ambientes cada vez mais próximos da realidade. Além disso, estes buscam criar, dentro do possível, uma visão sistêmica do ambiente. Estes novos métodos de ensino podem ser distintos em: jogo, cenário, 
simulação (que por si só pode ser um método de ensino) e método case (SOUZA; CHAGAS; SILVA, 2009).

Entre estes diversos métodos de ensino, segundo Antonio, Wermeck e Pires (2005), existe uma relação de dependências que não são aplicadas a todos os casos. Segundo os autores, o método "cenário" pode conter, internamente, um jogo ou um case e esse, por sua vez, um jogo. Tais relações são apresentadas na Figura 1.

Figura 1 - Relações entre os métodos de ensino

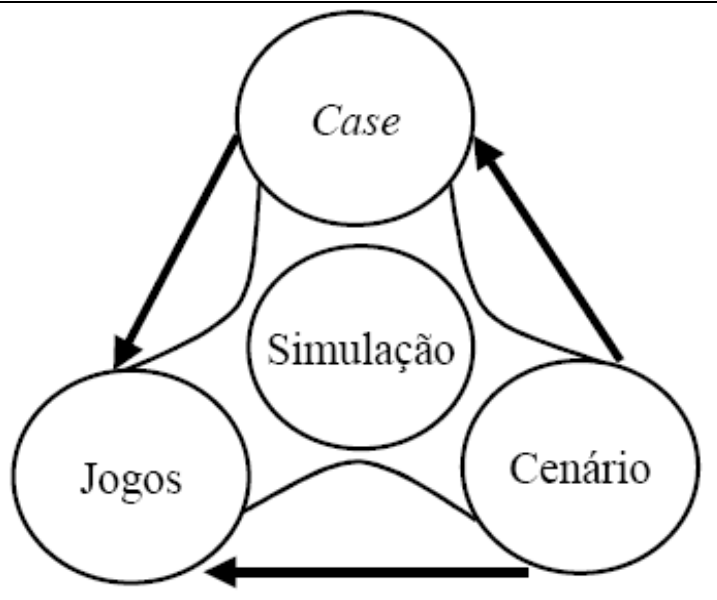

Fonte: Antonio, Wermeck; Pires (2005)

O desenvolvimento de uma proposta de jogos simulados, segundo Riis, Johansen e Mikkelsen (1995), deve estar pautado em sete características, as quais foram trabalhadas durante a criação deste trabalho. Estas características e abordagens utilizadas são apresentadas no Quadro 1.

Quadro 1 - Características para desenvolvimento de jogos simuladas e abordagem utilizada

\begin{tabular}{|l|l|}
\hline \multicolumn{1}{|c|}{$\begin{array}{c}\text { Característica do desenvolvimento de } \\
\text { jogos simulados }\end{array}$} & \multicolumn{1}{c|}{ Abordagem utilizada } \\
\hline $\begin{array}{l}\text { Possuir foco claro e restrito a poucos } \\
\text { temas }\end{array}$ & $\begin{array}{l}\text { A simulação apresenta-se focada em conceitos relativos ao sistema Lean } \\
\text { Production e suas ferramentas. }\end{array}$ \\
\hline Nível do jogo adequado aos participantes & $\begin{array}{l}\text { O nível do jogo concentra-se para alunos a partir do quinto semestre, os } \\
\text { quais já possuem conceitos mais bem definidos, podendo-se obter } \\
\text { resultados mais positivos da dinâmica. }\end{array}$ \\
\hline Conhecimento do tema pelos participantes & $\begin{array}{l}\text { A aplicação da dinâmica é aconselhada no final do semestre, de forma } \\
\text { que o aluno possa utilizar e correlacionar os assuntos desenvolvidos. }\end{array}$ \\
\hline $\begin{array}{l}\text { Representação de um ambiente real, para } \\
\text { que os participantes possam fazer analogia } \\
\text { com a realidade }\end{array}$ & $\begin{array}{l}\text { A simulação apresenta-se em torno de uma empresa fictícia, que, no } \\
\text { entanto, possui características e desafios a serem alcançados por } \\
\text { empresas reais. }\end{array}$ \\
\hline $\begin{array}{l}\text { Nível de abstração de acordo com as } \\
\text { limitações dos participantes, não } \\
\text { contendo, se possível, pontos ambíguos }\end{array}$ & $\begin{array}{l}\text { Os objetivos e os desafios a serem solucionados pelos alunos são } \\
\text { destacados no início da dinâmica, delimitando o tema abordado e } \\
\text { focando o assunto a ser trabalhado. }\end{array}$ \\
\hline $\begin{array}{l}\text { Resultado mensurável, de preferência } \\
\text { quantitativamente }\end{array}$ & $\begin{array}{l}\text { Os resultados obtidos nas diversas fases da simulação são representados } \\
\text { quantitativamente por meio do auxilio de planilhas eletrônicas, as quais } \\
\text { permitem a comparação entre os resultados obtidos durante as fases. }\end{array}$ \\
\hline $\begin{array}{l}\text { Conter direcionadores, tais como, } \\
\text { desafios, competição e pressão }\end{array}$ & $\begin{array}{l}\text { São apresentados no início da dinâmica, com o intuito de direcionar e } \\
\text { focalizar os esforços desenvolvidos. }\end{array}$ \\
\hline
\end{tabular}

Fonte: Autoria própria (2011) 
$\mathrm{Na}$ literatura nacional o uso de simulação e jogos empresariais na engenharia de produção apresenta-se restrito há poucos trabalhos, que abordam temas comumente estudado no campo da Engenharia de Produção. O Quadro 2 descreve brevemente alguns desses trabalhos.

Quadro 2 - Artigos científicos nacionais sobre jogos e simulação na Engenharia de Produção

\begin{tabular}{|c|c|c|}
\hline Autor & Foco & Tema \\
\hline Queiroz e Lucero (2009) & $\begin{array}{l}\text { Ensino Administração da } \\
\text { Produção }\end{array}$ & $\begin{array}{l}\text { Uso de jogo empresarial para ensinar conceitos } \\
\text { relativos a administração da produção e } \\
\text { planejamento e controle da produção }\end{array}$ \\
\hline Rodrigues e Cavagnari (2006) & Ensino de Administração & $\begin{array}{l}\text { Uso de jogo empresarial para o ensino de conceitos } \\
\text { relativos à gestão de negócios }\end{array}$ \\
\hline Pinho, Leal e Almeida (2005) & $\begin{array}{l}\text { Ensino de Gestão de } \\
\text { Operações }\end{array}$ & $\begin{array}{l}\text { Uso de Bloquinhos de Montagem para o ensino de } \\
\text { ferramentas de Gestão de Operações }\end{array}$ \\
\hline $\begin{array}{l}\text { Ambrósio, Braga, } \\
(2009)\end{array}$ & $\begin{array}{l}\text { Ensino de Planejamento e } \\
\text { Controle da Produção e } \\
\text { Gestão da Cadeia de } \\
\text { Suprimentos }\end{array}$ & $\begin{array}{l}\text { Uso da simulação baseada no BeerGame, } \\
\text { desenvolvido pelo MIT, o qual trabalho conceitos } \\
\text { relativos a Planejamento e Controle da Produção e } \\
\text { Gestão da Cadeia de Suprimentos. }\end{array}$ \\
\hline
\end{tabular}

Fonte: Autoria própria (2011)

Com isso, o método para elaboração da dinâmica de simulação do Sistema de Produção Enxuta seguiu o modelo apresentado na Figura 2.

Figura 2 - Método de desenvolvimento da simulação

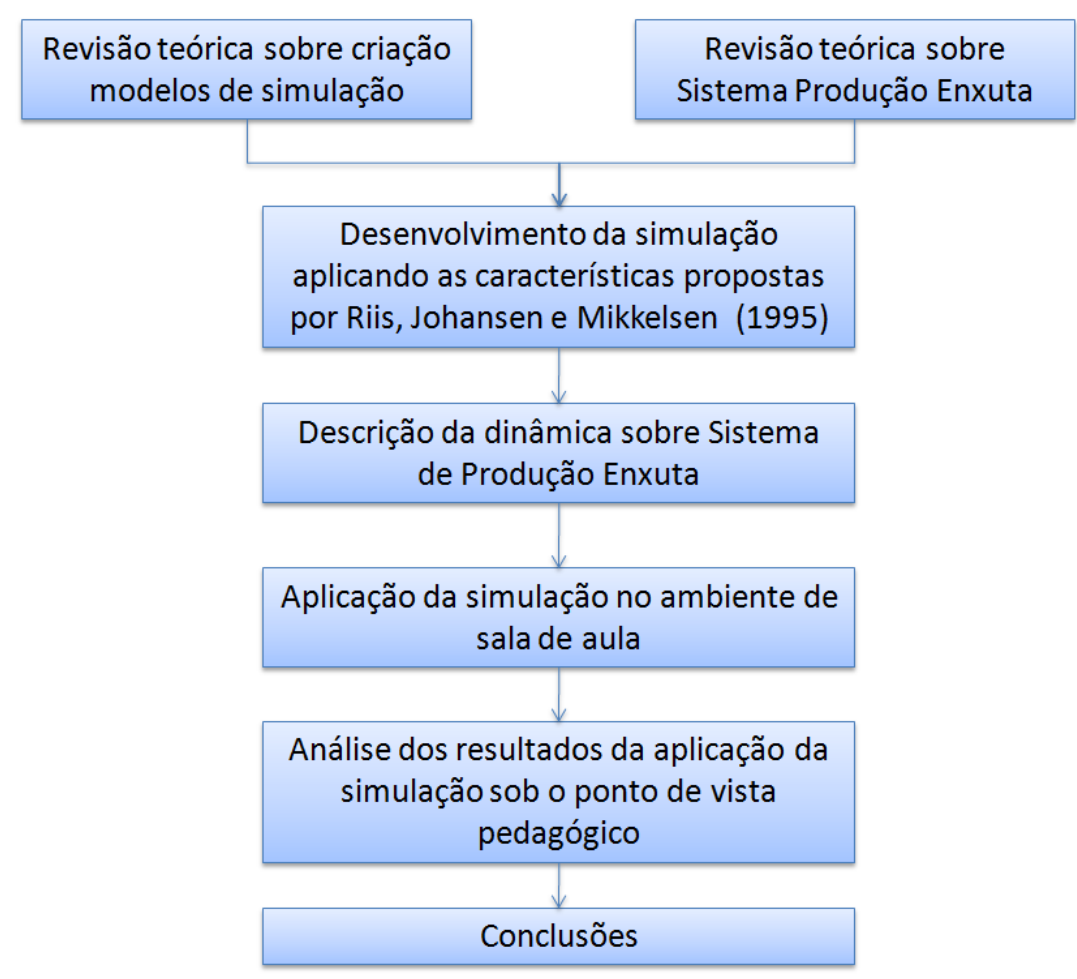

Fonte: Autoria própria (2011)

\section{Dinâmica de simulação do sistema produção enxuta}

Nesta seção serão descritos os aspectos relativos à proposta de criação de um ambiente fabril simulado, no qual permite a 40 alunos aplicarem os conceitos aprendidos durante o semestre letivo relacionados ao Sistema de Produção Enxuta. 


\subsection{Caracterização da empresa}

A simulação inicia com a apresentação da empresa e dos desafios impostos as pessoas que nela trabalham (neste caso os alunos). A narrativa da simulação desenvolve-se da seguinte maneira: “A POLIair atua no ramo de aeromodelismo há dois anos. A empresa produz em seu parque fabril três modelos de aviões: tradicional (modelo básico), morcego (modelo intermediário), e wide fire (modelo luxo). Nos últimos três meses a empresa vem passando por um processo de crescimento superior ao esperado. No entanto, a empresa não dispõe de recursos para investimentos de grande porte, como aquisição de novos maquinários ou a criação de um segundo turno de trabalho. Em vista disso a empresa tem buscado alternativas que permitam continuar crescendo e atendendo ao mercado."

\subsection{O ambiente fabril atual}

A POLIair dispõe atualmente de uma área planta fabril a qual conta com 40 colaboradores, que possuem funções especificas e estão distribuídos da seguinte maneira:

-Almoxarife (três colaboradores) - responsável pela separação do material a ser enviado à fábrica;

-Transportador (dois colaboradores) - responsável pelo transporte de materiais entre os processos produtivos;

-Montador (12 colaboradores) - divididos entre as 3 linhas de produtos da empresa (4 colaboradores em cada linha de produção: tradicional, morcego e wide fire), são responsáveis pelo processamento dos itens;

-Inspetor de Qualidade (três colaboradores) - responsável pela inspeção dos produtos fabricados no final da linha de montagem, e que serão encaminhados para posterior embalagem;

-Embalagem (seis colaboradores) - responsável pelo empacotamento dos aviões prontos.

-Supervisor de produção (dois colaboradores) - responsável pela supervisão e manutenção do ritmo da produção;

-Cronoanalista (três colaboradores) - responsável pela medição dos tempos de atividades;

-Analista de dados (três colaboradores) - responsável pela coleta de dados junto aos cronoanalistas

Os colaboradores apresentam-se dispostos no ambiente fabril o qual já possui um layout prédefinido pelos proprietários da empresa quando estes iniciaram suas atividades. Este layout é apresentado na Figura 3. 
Figura 3 - Layout inicial da fábrica de aeromodelos

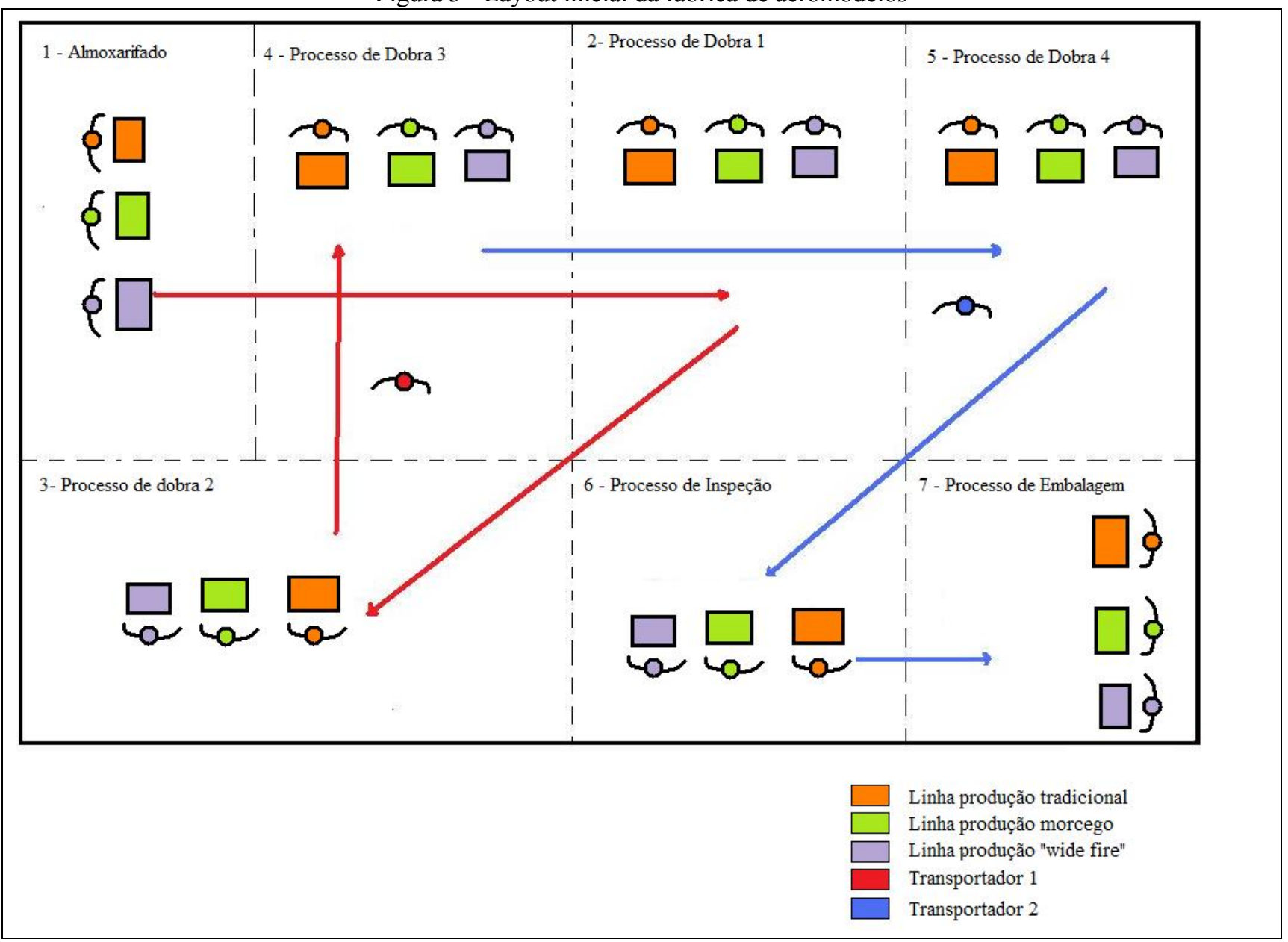

Fonte: Autoria própria (2011)

Como em todo ambiente fabril, as empresas possuem parâmetros que impactam em seus sistemas produtivos, tais como: o custo por unidade produzida, o custo de retrabalho/rejeição de uma unidade, o preço de venda do produto, a produção diária necessária para atender a demanda, entre outros. Estes aspectos são demonstrados no Quadro 3.

Quadro 3 - Parâmetros fabris iniciais

\begin{tabular}{|l|c|c|c|}
\hline \multicolumn{1}{|c|}{ Modelo } & Tradicional & Morcego & Wide Fire \\
\hline Produção diária (peças/dia) & 100 & 70 & 50 \\
\hline Produção em lote (peças/lote) & 8 & 6 & 5 \\
\hline Tempo produção disponível (min.) & 30 min & 30 min & 30 min \\
\hline Custo por unidade produzida & $\mathrm{R} \$ 4,50$ & $\mathrm{R} \$ 5,20$ & $\mathrm{R} \$ 7,60$ \\
\hline Custo peça refugada/retrabalhada & $\mathrm{R} \$ 6,00$ & $\mathrm{R} \$ 8,40$ & $\mathrm{R} \$ 11,90$ \\
\hline Preço de venda dos produtos & $\mathrm{R} \$ 12,00$ & $\mathrm{R} \$ 17,50$ & Laranja \\
\hline Cor avião & Roxo & Verde & \\
\hline
\end{tabular}

Fonte: Autoria própria (2011)

\subsection{Treinamento}


Após a apresentação da empresa, da divisão das atividades entre os participantes e a caracterização do atual ambiente fabril, é realizado o treinamento inicial onde é demonstrada na prática qual tarefa este irá realizar. Nesta etapa é importante apresentar aos participantes as tabelas as quais terão de preencher, o trajeto que terá de percorrer, as operações que terão de realizar para montagem dos modelos, entre outros aspectos necessários.

De forma a validar esta etapa, é aconselhada a realização de uma rodada de treinamento (baseada na liberação de um lote de fabricação), onde o mediador da simulação acompanha o processo e as tarefas de forma a esclarecer as dúvidas.

Tal etapa é importante, pois evita paradas desnecessárias da simulação quando esta já estiver ocorrendo para se retirar dúvidas relativas à montagem dos produtos.

\subsection{Rodada 1: produção em lotes}

Terminada a rodada de treinamento e retirada das últimas dúvidas, inicia-se a jornada de produção dos itens. Nesta fase os participantes da dinâmica possuem 30 minutos para a fabricação dos itens, sendo o objetivo principal atender a demanda estabelecida.

Cabe destacar, que nesta etapa é de vital importância o papel dos supervisores, os quais devem exercem pressão sobre as linhas de produção para que estas atinjam a meta, ao mesmo tempo que devem verificar se os produtos estão sendo desenvolvidos dentro dos padrões de fabricação por lote.

Os inspetores de qualidade devem estar atentos aos produtos que chegam, de modo a verificar se estes se encontram dentro das especificações estabelecidas pelo mediador da dinâmica.

Os cronoanalistas precisam realizar as medições de tempo que serão repassadas aos analistas de dados, e que serão de grande importância para a comparação dos resultados ao final da dinâmica.

\subsection{Análise dos dados: rodada inicial}

Encerrado o tempo de produção, os dados iniciais devem ser tabulados (vide Figura 3 no anexo) de forma a permitir uma análise preliminar da atual situação da empresa.

Nesta fase é importante demonstrar aos participantes aspectos como: total de produtos fabricados, total de produtos conformes, total de produtos refugados/rejeitados, tempos de produção, tempo de valor agregado, tempo takt disponível x tempo takt realizado.

\subsection{Proposições e implementação de melhorias}

Esta etapa concentra grande parte do sucesso da dinâmica. Após envolver os participantes com a atual situação da empresa e fazê-los "vivenciar" o seu dia-dia sob um aspecto produtivo, 
estes deverão explorar o conhecimento adquirido nas aulas teóricas e ligá-los a atual situação da empresa, com o intuito de melhorar ao máximo o desempenho fabril.

Para isso, os participantes deverão possuir um intervalo para pensar e sugerir melhorias, sendo uma ferramenta útil para este processo o brainstorm. Uma sugestão que se apresentou útil, foi o desenvolvimento de uma tabela, na qual se permite não apenas anotar as sugestões recebidas como também ligá-las aos possíveis ganhos que a empresa obterá ao implantá-la e ao tema da aula a qual esta vinculada (Quadro 4).

\begin{tabular}{|c|c|c|}
\hline \multicolumn{2}{|c}{ Quadro 4 Tabela exemplificada para anotações das sugestões } \\
\hline $\begin{array}{c}\text { Melhoria Sugerida } \\
\text { células de produção } \\
\text { Pltossível Ganho }\end{array}$ & Tema (s) Relacionado (s) \\
\hline $\begin{array}{c}\text { Balanceamento da mão de obra nas } \\
\text { células }\end{array}$ & $\begin{array}{c}\text { Diminuição perdas relativas a transporte } \\
\text { Aumento produtividade } \\
\text { Diminuição do lead time }\end{array}$ & Layout \\
\hline $\begin{array}{c}\text { Realização de fluxo unitário } \\
\text { Remoção das atividades de } \\
\text { transporte }\end{array}$ & Aumento produtividade & $\begin{array}{c}\text { Balanceamento da } \\
\text { produção }\end{array}$ \\
\hline
\end{tabular}

Fonte: Autoria própria (2011)

Após análise das melhorias sugeridas pelos participantes, estas são implantadas buscando obter um melhor desempenho operacional da empresa. É esperado nesta etapa que os participantes tenham diagnostico possíveis melhorias no layout organizacional, no fluxo de produção, na possibilidade de formação de células de manufatura, no fluxo unitário de produção, entre outros aspectos.

\subsection{Rodada 2: novo fluxo fabril}

Após o novo fluxo fabril ser desenvolvido e um breve treinamento realizado inicia-se novamente a produção fabril em um período de tempo igual ao anterior. Deve-se ter atenção para os mesmos aspectos citados na rodada inicial (item 3.4).

\subsection{Análise dos dados: rodada 2}

Assim como na análise de dados da primeira rodada, encerrado o tempo de produção os dados devem ser tabulados (vide Figura 3 no anexo) de forma a permitir uma análise da nova situação da empresa.

Estes dados devem ser então comparados aos dados anteriores destacando aos participantes os benefícios das mudanças realizadas (vide Figura 4 no anexo). É importante enaltecer a relação 
entre as propostas de melhorias e a obtenção de ganhos no ambiente fabril.

\subsection{Encerramento da dinâmica}

O fechamento da dinâmica deve ser realizado destacando, de maneira resumida, o estado inicial da fábrica, as metas propostas e se estas foram alcançadas e o estado atual o qual a empresa ficou.

Além disso, deve-se reservar um intervalo de tempo aos participantes, de maneira similar a realizada no item 3.6, para que estes possam vislumbrar novas melhorias que ainda possam ser efetivadas.

Por fim, o mediador da dinâmica deve estimular que os participantes comentem quais foram às lições aprendidas, a proporem melhorias e outros aspectos que virem como pertinentes, devendo estas ser tabuladas para futuras melhorias na dinâmica (Quadro 5).

\begin{tabular}{|l|l|}
\hline \multicolumn{2}{l}{ Quadro 5 - Tabela proposta para cadastro de comentários dos participantes } \\
\hline Participante & Comentário \\
\hline Aluno 1 & xxxxxxxxxxxxxxxxxxxxxx \\
\hline Aluno 2 & xxxxxxxxxxxxxxxxxxxxxx \\
\hline Aluno n & xxxxxxxxxxxxxxxxxxxxxx \\
\hline
\end{tabular}

Fonte: Autoria própria (2011)

\section{Conclusões}

A implantação de novas metodologias de ensino é uma realidade. Cada vez mais novas formas de ensino vêm tendo destaque nas universidades. Contudo, o uso destes métodos ainda tem ocorrido de forma relativamente tímida, pois esses métodos demandam muitos recursos, em alguns casos financeiros e intelectuais.

O presente trabalho objetiva apresentar o desenvolvimento e aplicação de uma simulação como ferramenta didática para complementação do processo de aprendizado. Esta ferramenta visa suprir, de maneira inicial, a ausência de simulações, que é destacada por Antonio, Wermeck e Pires (2005), como pouco empregadas no ensino de engenharia de produção.

A aprendizagem vivencial (por meio dos jogos didáticos) faz com que o papel principal do processo de ensino-aprendizagem desloque para o discente, que passa a ser o centro do processo, diferentemente do ensino tradicional que enfoca o papel do professor. Isto facilita um envolvimento maior, pelo desejo da busca de aprendizado competitivo e cooperativo. $\mathrm{O}$ trabalho em grupo prevalece sobre a apresentação expositiva e individual do docente.

A dinâmica exposta visa trabalhar com conceitos ensinados no decorrer do semestre letivo e 
tratam tópicos relativos a produção enxuta, como: lotes de produção; padronização do trabalho, simplificação de operações; formação de células de manufatura; cálculo de tempo de ciclo, cálculo de takt time; aumento de velocidade e ritmo de trabalho; redução do tempo de atravessamento; diminuição de transporte; curva de aprendizagem; e atividades que agregam/não agregam valor.

A abordagem destes tópicos apresentam-se ainda distintos aos desenvolvidos pelas simulações criados por Queiroz e Lucero (2009), Rodrigues e Cavagnari (2006), Pinho, Leal e Almeida (2005, Ambrósio, Braga, Pereira (2009), sendo esta simulação uma nova ferramenta para aplicação e desenvolvimento da teoria.

O roteiro de criação (conjunto de passos e atividades) descrito contribui para a sistemática de processo do modelo de simulação aplicado junto aos alunos e permite um trabalho de captação de necessidades e limitações da empresa. Os diferentes passos e atividades configuraram como orientadores do desenvolvimento, dando suporte a um processo estruturado de criação.

Cabe ressaltar que, mesmo havendo a compreensão dos conceitos envolvidos na dinâmica pelos participantes, deve-se haver um planejamento prévio para o efetivo sucesso da dinâmica. Dúvidas sempre ocorrem durante a realização principalmente quando se trabalha com um elevado número de alunos, devendo sempre o professor esforçar ao máximo para manter a organização no ambiente.

Esta dinâmica vem sendo aplicada junto a alunos do curso de graduação de Engenharia de Produção da Faculdade Politécnica de Campinas e Faculdade de Jaguariúna desde 2008, tendo sido uma ferramenta de complementação as aulas teórica desenvolvidas no semestre letivo, tendo participado neste período aproximadamente 200 alunos. Quanto aos resultados, destaca-se por parte dos alunos a mudança imposta pela realização da dinâmica e a quebra da rotina de aulas. Os mesmos enfatizam que tópicos muitas vezes trabalhados apenas teoricamente podem ser experimentados na prática, demonstrando possíveis casos e dificuldades que enfrentarão no ambiente fabril. Apontam ainda que as mudanças propostas não param apenas na formação do layout do tipo linha, mas que podia-se ainda ser trabalhado o cálculo e implantação do kanban para dar continuidade a dinâmica, trabalhando com isso a ferramenta PDCA.

Nota-se ainda que a criação deste jogo possibilitou a geração de um modelo que aproximouse adequadamente a realidade. Os bons resultados obtidos estimulam a continuação dos estudos, com possibilidade de desdobramentos para outras áreas como Planejamento e Controle da Produção (PCP); Gestão da Qualidade e Gestão de Operações, haja vista a lacuna existente tanto na literatura como no ambiente de aprendizagem da Engenharia de Produção.

\section{Abstract}

The usage of games and simulation has been currently spread as a support tool to the learning 
process. Nonetheless, these are still restricted to few types in the production engineering learning, due to the difficulty in creating one of them. The current article tries to fulfill this need presenting an educational game for assembling paper planes. From a pre-structured factory, the participants are involved and stimulated to modify the industrial environment by means of knowledge acquired during the academic term. Several topics linked to the lean manufacture are mentioned, like: production lots; work standardization, simplification of operations; formation of manufacture cells; calculation of cycle time, calculation of takt time; increase in the work speed and rhythm; reduction in intermediation time; decrease on transportation; learning curve; and activities which aggregate/don't aggregate value. As a result, among several aspects, the improvement on the visualization and fixation of the transmitted concepts is noticeable, since the application of simulation demonstrate possible cases and difficulties they face in the industrial environment.

Key words: simulation; didactic game; plant paper airplane; lean production system.

\section{Referências}

AMBRÓSIO, B. G.; BRAGA, J. L.; PEREIRA, M. O. UFV BeerGame: intermediando o aprendizado em cadeias de fornecimento com simulação e jogos empresariais. In: SIMPÓSIO BRASILEIRO DE INFORMÁTICA NA EDUCAÇÃO, 17, Brasília. Anais... Brasília, 2006.

ANTONIO, D. G.; WERNECK, A. M. F.; PIRES, S. R. I. Simulação, cenários, jogos e cases aplicados no ensino da Engenharia de Produção. In: SIMPÓSIO DE ENGENHARIA DE PRODUÇÃO, 12, Bauru. Anais... Bauru, 2005.

BELLAN, Z. S. Andragogia em ação: como ensinar adultos sem se tornar maçante. Santa Bárbara d'Oeste: SOCEP Editora, 2005.

BENKO, C.; MC FARLAN, W. Methamorphosis in the auto industry. Strategy \& Leadership, v.31, n.4, p. 4-8, 2003. cross ${ }^{\text {ref }}$

DEPEXE, M. D.; DORNELES, J .B.; COSTA, A. C. F.; SANTOS, D.G.; HEINECK, L.F.M. Apresentação de um jogo didático como ferramenta de apoio ao ensino da produção enxuta. Revista Gestão Industrial, v. 02, n. 04, p. 140-151, 2006.

FELD, W.M. Lean manufacturing: tools, techniques, and how to use them. CRC Ed. 248 p, 2000.

FIGUEIREDO, R. S.; ZAMBOM, A. C.; SAITO, J. R. A introdução da simulação como ferramenta de ensino e aprendizagem. In: ENCONTRO NACIONAL DE ENGENHARIA DE PRODUÇÃO, 21, Salvador. Anais... Salvador, 2001 .

HUNTER, S.L. Ten Steps to Lean Production. FDM Management, p. 20-23, 2004.

LAW, A. M.; KELTON, W. D. Simulation modeling and analysis. 3rd ed. New York: McGraw Hill, 2000.

LEIS, R. P.; KLIPPEL, M.; PELLEGRIN, I.; ANTUNES JÚNIOR, J. A. A utilização de jogos de simulação computacional no ensino de administração da produção: um estudo comparativo da aplicação do PSP. In: ENCONTRO DA ANPAD, 30, Salvador. Anais... Salvador, 2006.

LIKER, J. K. MEIER, D. O modelo Toyota: manual de aplicação, Porto Alegre: Bookman, 2007

OLIVEIRA, F. P. S.; SOUZA, R. L. R.; MEDEIROS JUNIOR, J. V.; ANEZ, M. E. M. Aplicação da simulação empresarial no ensino da graduação. In: SIMPÓSIO DE ENGENHARIA DE PRODUÇÃO, 12, Bauru. Anais... Bauru, 2006.

PESSÔA, M. S. P.; MARQUES FILHO, P. A. Jogos de empresas: uma metodologia para o ensino de engenharia ou administração. In: CONGRESSO BRASILEIRO DE EDUCAÇÃO EM ENGENHARIA, 29, Rio Grande do Sul. Anais... Rio Grande do Sul, 2001. 
PINHO, A F.; LEAL, F.; ALMEIDA, D. A. Utilização de bloquinhos de montagem LEGO® para o ensino dos conceitos do Sistema Toyota de Produção. In: ENCONTRO NACIONAL DE ENGENHARIA DE PRODUÇÃO, 25, Porto Alegre. Anais... Porto Alegre, 2005.

PROENÇA JÚNIOR, D. Critérios para o uso de jogos pedagógicos. In: ENCONTRO NACIONAL DE ENGENHARIA DE PRODUÇÃO, 32, Ouro Preto. Anais... Ouro Preto, 2003.

QUEIROZ , A. A.; LUCERO, A. G. Jogos, uma alternativa para complementar o ensino da administração da produção. In: ENCONTRO DE EDUCAÇÃO EM ENGENHARIA, 6, Rio de Janeiro. Anais... Rio de Janeiro, 2000.

RAUCH-GEELHAAR, C.; JENKE, K.; THURNES, C. M. Gaming in industrial management - quality and competence in advanced training. Production Planning \& Control, v. 14, n. 2, p. 155-165, 2003.

cross ${ }^{\text {ref }}$

RIIS; J. O.; JOHANSEN; J.; MIKKELSEN; H. Design of simulation games: simulation games and learning in production management. Denmak. Chapman \& Hall, 1995.

ROBINSON, S. Simulation: the practice of model development and use. Chichester: John Wiley \& Sons, 2003.

RODRIGUES, E. M. Z.; CAVAGNARI, D. W. Jogos de empresas universitários UTP - sistema didático pedagógico de simulação de gestão de negócios. In: SEMINÁRIOS DE PESQUISA, 10, Paraná, 2006.

SCHRAMM, F.K.; FORMOSO, C.T. Uso de simulação interativa visual no projeto de sistemas de produção de empreendimentos da construção civil. In: ENCONTRO DE TECNOLOGIA DE INFORMAÇÃO E COMUNICAÇÃO NA CONTRUÇÃO CIVIL, 3, Porto Alegre. Anais... Porto Alegre, 2007.

SOUZA, A. V.; CHAGAS, F. A.; SILVA, C. E. Jogos de empresas como ferramenta de treinamento e desenvolvimento. Revista Campus, Paripiranga, v.2, n.1, p.6-30, 2009.

WOMACK, J. P., JONES, D. T., ROOS, D. A máquina que mudou o mundo. Ed. Campus, 2004.

\section{Dados dos autores}

Nome completo: Eduardo Guilherme Satolo

Filiação institucional: Faculdade Politécnica de Campinas - POLICAMP

Departamento: Engenharia de Produção

Função ou cargo ocupado: Professor Coordenador do Curso de Engenharia de Produção

Endereço completo para correspondência (bairro, cidade, estado, país e CEP): Av. Dona Jane

Conceição, 1385, Paulista, Piracicaba, São Paulo, Brasil, CEP 13403-040

Telefones para contato: (19) 9160-9659 ou (19) 3756-2300 ramal 226

e-mail:engproducao@policamp.edu.brouedusatolo@hotmail.com

Enviado em: 28/06/2010

Aprovado em:15/06/2011 
ANEXOS

\begin{tabular}{|c|c|c|c|c|c|c|c|c|c|c|c|c|c|c|c|c|c|}
\hline Modelo & 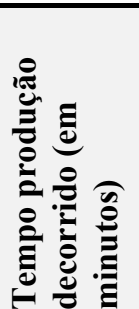 & 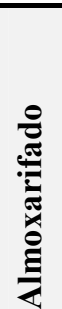 & 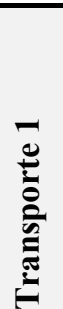 & $\begin{array}{l}\bar{\pi} \\
\overline{0}\end{array}$ & 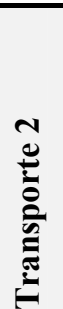 & 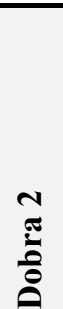 & 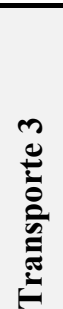 & 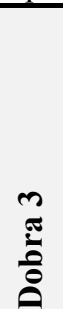 & 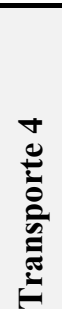 & 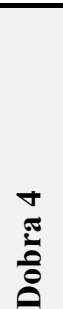 & 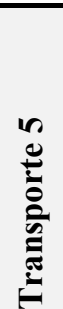 & 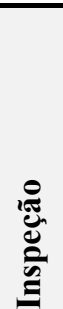 & 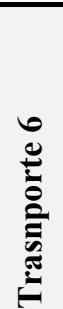 & 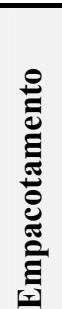 & 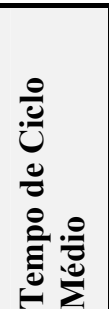 & 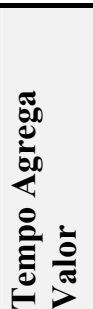 & 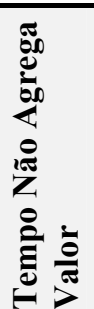 \\
\hline Cronometragem & 1 & & & & & & & & & & & & & & & & \\
\hline \multicolumn{18}{|c|}{ Tempo médio Acumulado } \\
\hline Tempo de Ciclo & & & & & & & & & & & & & & & & & \\
\hline
\end{tabular}

\begin{tabular}{|c|c|c|c|c|c|c|c|c|}
\hline Modelo & 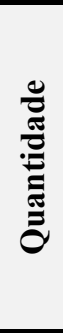 & 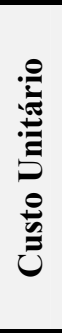 & 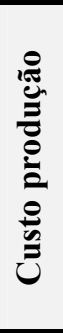 & 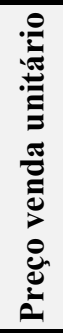 & 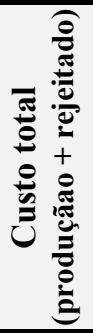 & 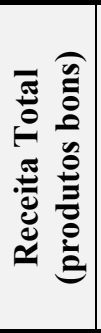 & & 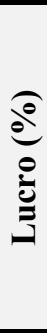 \\
\hline \multicolumn{9}{|c|}{ Unidades produzidas total } \\
\hline \multicolumn{9}{|l|}{ Unidades boas } \\
\hline Unidades rejeitadas & & & & & & & & \\
\hline
\end{tabular}

\begin{tabular}{|l|l|}
\hline \multicolumn{2}{|c|}{ Previsão } \\
\hline Demanda diária solicitada & \\
\hline Tempo disponível (seg.) & \\
\hline Takt time (seg/pç) & \\
\hline \multicolumn{2}{|c|}{ Realizado } \\
\hline Demanda produzida & \\
\hline Tempo disponível (seg.) & \\
\hline Takt Time realizado & \\
\hline
\end{tabular}

Fonte: Autoria própria (2011) 
Quadro 7 - Tabela de comparação dos resultados das rodadas

\begin{tabular}{|c|c|c|c|c|c|c|c|c|c|c|}
\hline \multirow{2}{*}{$\begin{array}{l}\text { Indicadores } \\
\text { Produção }\end{array}$} & \multicolumn{2}{|c|}{$\begin{array}{c}\text { Tempo Ciclo } \\
\text { (seg.) }\end{array}$} & \multicolumn{2}{|c|}{$\begin{array}{c}\text { Tempo Agrega } \\
\text { Valor (\%) } \\
\end{array}$} & \multicolumn{2}{|c|}{$\begin{array}{c}\text { Tempo Não Agrega } \\
\text { Valor (\%) }\end{array}$} & \multicolumn{2}{|c|}{ Takt Time } & \multicolumn{2}{|c|}{ Estoque em Processo } \\
\hline & $\begin{array}{c}\begin{array}{c}\text { Produção } \\
\text { lote }\end{array} \\
\end{array}$ & $\begin{array}{c}\text { Produção } \\
\text { celular }\end{array}$ & $\begin{array}{c}\text { Produção } \\
\text { lote }\end{array}$ & $\begin{array}{c}\text { Produção } \\
\text { celular }\end{array}$ & $\begin{array}{c}\text { Produção } \\
\text { lote }\end{array}$ & $\begin{array}{c}\begin{array}{c}\text { Produção } \\
\text { celular }\end{array} \\
\end{array}$ & $\begin{array}{c}\begin{array}{c}\text { Produção } \\
\text { lote }\end{array} \\
\end{array}$ & $\begin{array}{c}\text { Produção } \\
\text { celular }\end{array}$ & $\begin{array}{c}\text { Produção } \\
\text { lote }\end{array}$ & $\begin{array}{c}\begin{array}{c}\text { Produção } \\
\text { celular }\end{array} \\
\end{array}$ \\
\hline \multicolumn{11}{|l|}{ Tradicional } \\
\hline \multicolumn{11}{|l|}{ Morcego } \\
\hline Wide Fenix & & & & & & & & & & \\
\hline
\end{tabular}

\begin{tabular}{|c|c|c|c|c|c|c|}
\hline \multirow[b]{2}{*}{ Produção } & \multicolumn{2}{|c|}{ Qtdade Produzida } & \multicolumn{2}{|c|}{ Itens Refugados } & \multicolumn{2}{|c|}{ Itens bons } \\
\hline & $\begin{array}{c}\text { Produção } \\
\text { lote }\end{array}$ & $\begin{array}{c}\begin{array}{c}\text { Produção } \\
\text { celular }\end{array} \\
\end{array}$ & $\begin{array}{c}\text { Produção } \\
\text { lote }\end{array}$ & $\begin{array}{c}\text { Produção } \\
\text { celular }\end{array}$ & $\begin{array}{c}\text { Produção } \\
\text { lote }\end{array}$ & $\begin{array}{c}\begin{array}{c}\text { Produção } \\
\text { celular }\end{array} \\
\end{array}$ \\
\hline \multicolumn{7}{|l|}{ Tradicional } \\
\hline \multicolumn{7}{|l|}{ Morcego } \\
\hline \multicolumn{7}{|l|}{ Wide Fenix } \\
\hline Total & & & & & & \\
\hline
\end{tabular}

\begin{tabular}{|c|c|c|c|c|c|c|c|c|c|c|c|c|}
\hline \multirow{2}{*}{ Financeiro } & \multicolumn{2}{|c|}{ Custo Produção } & \multicolumn{2}{|c|}{ Custo Refugados } & \multicolumn{2}{|c|}{$\begin{array}{c}\text { Custo total } \\
\text { (Produção + Refugados) }\end{array}$} & \multicolumn{2}{|c|}{ Receita vendas } & \multicolumn{2}{|c|}{ Lucro Líquido } & \multicolumn{2}{|c|}{ Margem Lucro } \\
\hline & $\begin{array}{l}\text { Produção } \\
\text { lote }\end{array}$ & $\begin{array}{c}\begin{array}{c}\text { Produção } \\
\text { celular }\end{array} \\
\end{array}$ & $\begin{array}{c}\text { Produção } \\
\text { lote }\end{array}$ & $\begin{array}{c}\begin{array}{c}\text { Produção } \\
\text { celular }\end{array} \\
\end{array}$ & $\begin{array}{c}\text { Produção } \\
\text { lote }\end{array}$ & $\begin{array}{c}\text { Produção } \\
\text { celular }\end{array}$ & $\begin{array}{l}\text { Produção } \\
\text { lote }\end{array}$ & $\begin{array}{c}\text { Produção } \\
\text { celular }\end{array}$ & $\begin{array}{c}\text { Produção } \\
\text { lote }\end{array}$ & $\begin{array}{c}\text { Produção } \\
\text { celular }\end{array}$ & $\begin{array}{c}\text { Produção } \\
\text { lote }\end{array}$ & $\begin{array}{c}\begin{array}{c}\text { Produção } \\
\text { celular }\end{array} \\
\end{array}$ \\
\hline \multicolumn{13}{|l|}{ Tradicional } \\
\hline \multicolumn{13}{|l|}{ Wide Fenix } \\
\hline Total & & & & & & & & & & & & \\
\hline
\end{tabular}

Fonte: Autoria própria (2011) 